\title{
The Journal of Respiration (JoR): A New Open Access Journal Dedicated to the Timely Dissemination of Information Related to Thoracic Structures
}

\author{
Cesar A. Moran \\ Anderson Cancer Center, University of Texas MD, Houston, TX 77030, USA; CesarMoran@mdanderson.org \\ Received: 22 February 2021; Accepted: 23 February 2021; Published: 26 February 2021

\section{Introduction}

Over the last decade, the amount of information pertaining to thoracic structures has been unprecedented. The thorax is unique in terms of the different structures that involve the respiratory system-lungs, pleura, upper and lower respiratory tract-all located in the mediastinum that by itself represents a different compartment with its own wealth of conditions, and that also includes the Thymic gland. Therefore, we believe that the availability of a new open access journal, JoR, dedicated to highlighting and disseminating information related to the respiratory system is not only timely but is also absolutely necessary. The developments in diagnostic methodologies and ancillary tools in respiratory medicine, surgery, diagnostic imaging, oncology, pathology, immunohistochemistry, and molecular diagnostics with next generation sequencing and targeted therapies have transformed the areas of thorax with a wealth of information, which lend themselves appropriately for inclusion in our journal as the perfect tribune for such publications. Even though there seems to be an affinity for oncological conditions, we cannot overlook the wide range of medical diseases, including congenital malformations, metabolic, and physiological conditions that have also generated a wealth of information in the adult, as well as in the pediatric population. More importantly, we also want to highlight that we also believe that the dissemination of information pertaining to the respiratory systems should not be limited to pathological conditions, but also to the dissemination of information that also highlights new information on normal development, new clues on histological discoveries, nuances on diagnostic tools, and very importantly the timely information on biomarkers and bioinformatics that currently play an important role in medicine in general. We also hope that our journal will host information related to artificial intelligence, as it is applied to any area of the respiratory system. As we can see, the information related to the respiratory systems is vast and there could not be anything more and better than to have a journal that is dedicated to the promotion, dissemination, and efficient publication of timely articles on the respiratory system including all its structures.

Needless to say, we have assembled a highly reputable Editorial Board capable of providing guidance for the future and well-being of our journal, and at the same time providing helpful and constructive criticism for any material that is to be published in JoR. In addition, we count with the commitment of the publisher and the administrative supporting personnel that together with the Editorial Board will make of $J o R$ the journal of choice for your manuscripts.

Finally, on behalf of our Editorial Board and Administrative support, we want to welcome your work and hope we can build the trust that you as an author deserve. Together we will see the growth and the success of JoR. I very much look forward to working with you. 
Funding: This research received no external funding.

Conflicts of Interest: The author declares no conflict of interest.

Publisher's Note: MDPI stays neutral with regard to jurisdictional claims in published maps and institutional affiliations.

(C) 2021 by the author. Licensee MDPI, Basel, Switzerland. This article is an open access article distributed under the terms and conditions of the Creative Commons Attribution (CC BY) license (http://creativecommons.org/licenses/by/4.0/). 